\title{
Comparative Susceptibility of Adult African Invader Fly Bactrocera invadens (Diptera: Tephritidae) to Some Selected Insecticides in Ghana
}

\author{
G. Abdullahi ${ }^{1}$, H. Sule ${ }^{2}$, D. Obeng-Ofori ${ }^{3}$, K. Afre-Nuamah ${ }^{4} \&$ M. K. Billah ${ }^{5}$ \\ ${ }^{1}$ Department of Crop Protection, Modibbo Adama University of Technology, Yola, Nigeria \\ ${ }^{2}$ Department of Crop Science, Adamawa State University, Mubi, Adamawa State, Nigeria \\ ${ }^{3}$ Department of Crop Science, University of Ghana, Legon \& African Regional Postgraduate Programme in \\ Insect Science, University of Ghana, Legon, Accra, Ghana \\ ${ }^{4}$ Agricultural Research Centre, Kade, Institute of Agricultural Research, University of Ghana, Legon, Accra, \\ Ghana \\ ${ }^{5}$ Department of Animal biology and Conservation Science, University of Ghana, Legon, Accra, Ghana \\ Correspondence: G. Abdullahi, Department of Crop Protection, Modibbo Adama University of Technology, P. M. \\ B. 2076 Yola, Nigeria. E-mail: gatsaranyi@yahoo.com
}

Received: February 9, 2012 Accepted: March 3, 2012 Online Published: July 11, 2012

doi:10.5539/jas.v4n8p182 URL: http://dx.doi.org/10.5539/jas.v4n8p182

\begin{abstract}
With the recent introduction of $B$. invadens in Africa and its devastating role in crop production, especially mango, with currently no registered insecticides for use against this fly in Ghana, the susceptibility of the fly to four commercially available insecticidal products namely, Cydim Super, Pyrinex 48 EC, Diazol 50 EW and Deltapaz was evaluated in the laboratory. The bioassay was conducted using three (3) different doses of each insecticidal product, by dipping $4 \times 4 \mathrm{~cm}$ hardboard panels into the respective doses. Susceptibility of the flies to insecticides were assessed on freshly treated panels, 3-day-old and 6-day-old treated panels in some ventilated transparent bottles of 1 litre capacity. Adult flies aged between 4-12 days were used for the bioassays. The bioassay results indicated that the adult flies were more susceptible to Diazol (Diazinon) $\left(\mathrm{LC}_{50}=0.6 \mathrm{ml} / \mathrm{L} ; \mathrm{LC}_{90}\right.$ $=1.3 \mathrm{ml} / \mathrm{L})$ and Pyrinex (Chlorpyrifos) $\left(\mathrm{LC}_{50}=0.8 \mathrm{ml} / \mathrm{L} ; \mathrm{LC}_{90}=1.0 \mathrm{ml} / \mathrm{L}\right)$, and hence gave the least $\mathrm{LT}_{50}$ and $\mathrm{LT}_{90}$ times. Least susceptibility was recorded with Deltapaz (Deltamethrin) $\left(\mathrm{LC}_{50}=3.1 \mathrm{ml} / \mathrm{L} ; \mathrm{LC}_{90}=5.2 \mathrm{ml} / \mathrm{L}\right.$ ). It could be concluded that the control of $B$. invadens can be achieved more effectively by the use Pyrinex (Chlorpyrifos) and Diazol (Diazinon). The use of Pyrinex appears to be more economical to the resource poor farmers as it had least $\mathrm{LC}_{90}$ of $1.0 \mathrm{ml} / \mathrm{L}$ compared to $1.3 \mathrm{ml} / \mathrm{L}$ for Diazol in $30 \mathrm{~min}$.
\end{abstract}

Keywords: Laboratory evaluation, Bactrocera invadens, Susceptibility, Insecticides, Ghana

\section{Introduction}

Bactrocera invadens is a recently described invasive fruit fly species of Asian origin (Drew et al., 2005) accidentally introduced into Africa probably from Sri Lanka (Lux et al., 2003b; Billah et al., 2006). In Africa it has been recorded from Benin, Cameroun, Democratic republic of Congo, Ethiopia, Gabon, Ghana, Guinea, Kenya, Togo, Mali, Nigeria, Senegal, Sudan, and Uganda (Drew et al., 2005; Ekesi \& Billah, 2006). In Ghana, Billah et al. (2006) detected the presence of B. invadens in three regions i.e. Greater Accra, Eastern and Volta Regions in 2005. Bactrocera invadens appears to be highly polyphagous and may be expected to have a broad host range as $B$. dorsalis. It has been reared from mango, lemon, orange, tomato, banana, guava, marula, custard apple, Indian almond, and papaya, among other hosts (Ekesi \& Billah, 2006; Rwomushana et al., 2008). Mango, however, appears to be the primary host plant (Ekesi et al., 2006).

Globally, mango is the second most important tropical fruit traded internationally (ICIPE, 2007). In East and West Africa, over $80 \%$ of the produce comes from smallholders for both domestic urban and export markets of which the EU is the major export destination (ICIPE, 2007). In Ghana, the volume of mango produced increased from 182 tonnes in 2006 to 827 tonnes in 2007, representing 354\% increase over the period. The corresponding values of earnings increased from $\$ 83,200$ in 2006 to $\$ 998,160$ in 2007, representing a percentage increase of $1,099 \%$ (ISSER, 2008). This increment represents the second largest in terms of foreign earnings from 
non-traditional export over the period (ISSER, 2008). The production of this important crop in Ghana is currently being constrained by the presence of $B$. invadens and other fruit fly species.

Current control measures against fruit flies mostly incorporate the use of insecticides as a cover spray or bait and targeting the adult flies (Raga \& Sato, 2006). Because female fruit flies lay eggs beneath the exocarp of the fruit and the larvae develop inside the fruit with little chance of insecticide affecting them (Moreno et al., 1994), any integrated pest management strategy to control B. invadens in Ghana may involve the use of insecticides as spot sprays and/or bait on the adult flies. This is because if the fly population becomes too large, there is no control method that will be cost effective against the flies. One of the only effective strategies for interrupting the developmental cycle of the flies is to remove the fallen fruits and by prevent adult flies from implanting eggs in the fruit by the use of baited traps and preventive insecticide treatment (CTA, 2007).

Several insecticides are registered in Ghana for the control of arthropod pests including fruit flies in the mango agro-ecosystem. Some of the most common ones include Chlorpyrifos, Cypermethrin, Deltamethrin, Lambda-cyhalothrin, bifenthrin, Azadirachtin, Dimethoate, White oils and Thiamethxam (EPA, 2008). However, there is death of information in the literature on the susceptibility of the adult $B$. invadens to any of these insecticides, as they were registered for pest control before the arrival of $B$. invadens. The objectives of this study was to generate information on the efficacy of the most commonly used insecticides by farmers in Ghana to control this quarantine pest, namely Cydim Super, Pyrinex 48 EC, Diazol 50 EW and Deltapaz.

\section{Materials and Methods}

\subsection{Collection of Fruits for the Establishment of B. invadens Colony}

Mango fruits were collected from the University of Ghana farm, at Legon, Agricultural Research Centre, at Kade and its environs, and from different locations within the University environment. Fruit samples collected included unripe, overripe and rotten ones as windfalls (Rwomushana et al., 2008). Fruits collected were packaged in bagco sacks (Sino PP woven bag, Danzaki Ltd., Kano, Nigeria) with the tops left open to provide adequate ventilation and taken to the laboratory for rearing out of the fruit flies.

\subsection{Rearing of Fruit Flies}

Fruits collected from various locations were processed in the laboratory for rearing of the fruit flies as described by Copeland (2006) and Rwomushana et al., (2008). Fruits were placed on large plastic racks with trays of pre-sterilized moistened sand under the container to collect exiting larvae. Fruits were also incubated in plastic bowls lined with sand. The sand was heat-sterilized at $100{ }^{\circ} \mathrm{C}$ for $12 \mathrm{~h}$. Fruits were dissected after 2 weeks of incubation to remove any remaining larvae as larvae may sometimes prefer to remain inside the rotting fruit if the outside environment is not conducive (Billah, personal communication). After 3 days, the sand was sieved to recover puparia, which were placed in petri dishes lined with moist filter paper. Daily checks for emerged insect was done and insects transferred into holding cages. Adult insects were allowed to stay for 3-4 days to achieve full adult characteristics to facilitate proper identification. They were provided with water-soaked cotton wool and fed on a diet containing pure baker's yeast and sugar (1 part yeast:3 part sugar, vol./vol. combination). Insects were separated according to species and kept in different cages. Parasitoids and non-tephritid flies were also separated.

\subsection{Identification of Flies}

Flies were identified using literature and keys of White and Elson-Harris (1992), De Meyer (1996, 1998, 2000) and Billah and Mansell (2006). Where there was doubt, flies were sent to Dr. M. K. Billah (Zoology Department, University of Ghana) for confirmation. Flies were sorted according to species. Non-tephritids flies were killed.

\subsection{Culturing of Flies}

The emerged adults were cultured in cages on artificial diet prepared with three parts sugar and one part pure bakers' yeast (vol./ vol.) diet (Ekesi et al., 2006). Few drops of honey were added /spotted on the underside of the roof of the cage and cotton wool soaked with tap water was placed in small container on the floor of the cage. The cages were occasionally cleaned to maintain good environment.

\subsection{Insecticides Selected for the Study}

Four insecticides namely; Cydim Super, Pyrinex 48 EC, Diazol 50 EW and Deltapaz were evaluated during the study. The insecticides used for the studies were purchased from two Agro-chemical dealers; Agri- mat and Dizengoff Ghana Ltd. 


\subsection{Insecticide Efficacy Bioassay}

Before exposure of the adult insects to Respective insecticides, their LC50 and LC90 were determined within the period of five (5) minutes exposures using EPA probit analysis version 1.5. Insecticide efficacy was determined by calculating the lethal time $\left(\mathrm{LT}_{50}\right.$ and $\left.\mathrm{LT}_{90}\right)$ values for the field strain of adult $B$. invadens for each formulation. All bioassays were conducted in the research Laboratory at the African Regional Postgraduate Programme in Insect Science (ARPPIS) building, University of Ghana, Legon, under $28 \pm 2^{\circ} \mathrm{C}$, RH $68-81 \%$ and photoperiod of 12:12 D:L hours. Bioassays were conducted in one litre transparent bottles fitted with yellow caps, from which treated hardboard panels $(4 \mathrm{x} 4 \mathrm{~cm})$ were hanged. A hundred and fifty $(150)$ holes of $1.5 \mathrm{~mm}$ diameter were made on the sides of the bottles for ventilation during the bioassay (Cheng et al., 2009). A hole of $1.5 \mathrm{~mm}$ in diameter was made at the centre of the bottles' yellow cap to hang the treated panels with the aid of a string attached to the panels.

Hardboard panels were dipped into a solution of the test insecticides at three different concentrations for each insecticidal product, viz: $10 \mathrm{ml}$ below the manufacturers recommended dose (Lowest doses), the manufacturers recommended doses (median doses), and $10 \mathrm{ml}$ above the manufacturers recommended doses (Highest doses) (Moore \& Miller, 2006). Thus, 1.6, 2.3, and $3.0 \mathrm{ml}$ of Cydim Super per litre of water were used for bioassay, Pyrinex $48 \mathrm{EC}$ was used at the rate of $0.9,1.0$, and $1.10 \mathrm{ml}$ per litre of water, Diazol $50 \mathrm{EW}$ was used at the rate of 1.8, 2.5, and $3.2 \mathrm{ml}$ per litre of water, and Deltapaz was used at the rate of 2.6, 3.4 and $4.0 \mathrm{ml}$ per litre of water. The hardboard panels were treated by dipping into the respective concentrations of the insecticidal product. Ten adult flies of mixed sexes ( 5 males and 5 females) aged 4-12 days were collected from the rearing cages using a $1.5 \mathrm{~cm}$ diameter vial. These were introduced into the bioassay bottles containing the treated panels. The bottles were placed upright.

Observations for mortalities were made at least once every 5 minutes. Adult flies that were knocked down and could not move any appendages for 30 seconds after responding to the insecticides were considered, and scored dead. The times taken for 50 and $90 \%$ of the introduced flies to die were recorded to represent $\mathrm{LT}_{50}$ and $\mathrm{LT}_{90}$, respectively for a treatment and dosage level.

Three experiments were conducted based on the age (in days) of the treated panels:

- (1) Freshly treated panels (10 minutes after dipping).

- (2) 3-day old treated panels (72 hours after dipping).

- (3) 6-day old treated panels (144 hours after dipping) (Urbaneja et al., 2009).

This gave the residual toxicity (persistence) of each of the candidate insecticides under study over six days period. A similar panel treated with only water before exposure to insects, was used as a control for the different doses of the four insecticides.

\subsection{Data Analysis}

Data from laboratory bioassay of insecticidal products were analysed using ANOVA with the GENSTAT statistical packages (GenStat Release 9.2 (PC/Windows) 2007, Lawes Agricultural Trust (Rothamsted Experimental Station) 9th Edition). The results were presented as tables and means were separated using Least Significant difference (LSD, $\mathrm{P}<0.05$ ). Mortality exceeding $10 \%$ in the control was corrected using Abbotts' formula (Abbott, 1925).

\section{Result}

\subsection{Insecticides Efficacy Bioassay}

\subsubsection{Lethal Concentrations}

The Lethal concentration results indicated that the adult flies were more susceptible to Diazol (Diazinon) $\left(\mathrm{LC}_{50}=\right.$ $\left.0.6 \mathrm{ml} / \mathrm{L} ; \mathrm{LC}_{90}=1.3 \mathrm{ml} / \mathrm{L}\right)$ and Pyrinex (Chlorpyrifos) $\left(\mathrm{LC}_{50}=0.8 \mathrm{ml} / \mathrm{L} ; \mathrm{LC}_{90}=1.0 \mathrm{ml} / \mathrm{L}\right)$, and hence gave the least $\mathrm{LT}_{50}$ and $\mathrm{LT}_{90}$ times. Least susceptibility was recorded with Deltapaz (Deltamethrin) $\left(\mathrm{LC}_{50}=3.1 \mathrm{ml} / \mathrm{L}\right.$; $\mathrm{LC}_{90}=5.2 \mathrm{ml} / \mathrm{L}$ )

\subsubsection{Freshly Treated Panels}

The results of the experiment with freshly treated panels are presented on table 1 . The results indicated that at the lowest doses, Diazol gave the least mean $\mathrm{LT}_{50}$ and $\mathrm{LT}_{90}$ values $(33.70 \pm 4.90$ and $48.00 \pm 7.0 \mathrm{~min}$, respectively). However, there was no significant difference $(\mathrm{P}>0.05)$ among the mean lethal times $\left(\mathrm{LT}_{50 \mathrm{~s}}\right)$ for Diazol, Pyrinex and Cydim Super. The highest mean $\mathrm{LT}_{50}$ and $\mathrm{LT}_{90}$ values $(360.33 \pm 24.91$ and $54.33 \pm 32.27 \mathrm{~min}$, respectively) were recorded on panels treated with Deltapaz. All treatments acted significantly faster $(\mathrm{P}<0.05)$ on the test 
insects than the control. Similarly, mean lethal time to mortality of $90 \%\left(\mathrm{LT}_{90}\right)$ of the adult $B$. invadens on panels freshly treated with Cydim Super were significantly higher $(\mathrm{P}<0.05)$ than those from panels treated with Pyrinex and Diazol, but lower than Deltapaz and the control.

At the median doses, there was no significant difference $(\mathrm{P}>0.05)$ among times to $50 \%$ mortality $\left(\mathrm{LT}_{50}\right)$ of the test insect on panels treated with Cydim Super, Pyrinex and Diazol. Deltapaz gave a significantly higher $(\mathrm{P}<$ $0.05)$ mean mortality time for $50 \%\left(\mathrm{LT}_{50}=317.33 \pm 61.76 \mathrm{~min}\right)$ of the test insects than all the other treatments except the control $\left(\mathrm{LT}_{50}=>2880.00 \mathrm{~min}\right)$.

Mean mortality time for $90 \%\left(\mathrm{LT}_{90}\right)$ of adult $B$. invadens under the medium dose experiment indicated that Cydim Super $\left(\mathrm{LT}_{90}=103.00 \pm 14.18 \mathrm{~min}\right)$ acted significantly slower $(\mathrm{P}<0.05)$ than both Diazol and Pyrinex, but significantly faster than Deltapaz $\left(\mathrm{LT}_{90}=462.00 \pm 17.95 \mathrm{~min}\right)$ and the control. All the treatments however, acted significantly faster $(\mathrm{P}<0.05)$ than the controls.

Table 1. Mean lethal time (LT) of the four insecticide on freshly treated panels

\begin{tabular}{|c|c|c|c|c|}
\hline \multirow[b]{2}{*}{ Dose level } & \multirow[b]{2}{*}{ Treatment } & \multirow[b]{2}{*}{ Doses $\mathrm{ml} / \mathrm{L}$} & \multicolumn{2}{|c|}{ Mean \pm S. E. lethal time $(\min )$} \\
\hline & & & $\mathrm{LT}_{50}$ & $\mathrm{LT}_{90}$ \\
\hline \multirow[t]{6}{*}{ LD } & Cydim super & 1.6 & $66.33 \pm 8.78$ & $128.00 \pm 20.81$ \\
\hline & Pyrinex & 0.9 & $66.33 \pm 16.50$ & $74.67 \pm 9.60$ \\
\hline & Diazol & 1.8 & $33.70 \pm 4.91$ & $48.00 \pm 7.0$ \\
\hline & Deltapaz & 2.6 & $360.33 \pm 24.91$ & $547.33 \pm 32.27$ \\
\hline & Control & 0.0 & $>2880.00 \pm 0.0$ & $>2880.00 \pm 0.00$ \\
\hline & LSD $(\mathrm{P}<0.05)$ & & 50.22 & 56.24 \\
\hline \multirow[t]{6}{*}{ MD } & Cydim Super & 2.3 & $62.00 \pm 15.52$ & $103.00 \pm 14.18$ \\
\hline & Pyrinex & 1.0 & $39.33 \pm 9.34$ & $56.67 \pm 14.18$ \\
\hline & Diazol & 2.5 & $34.67 \pm 3.76$ & $39.00 \pm 7.00$ \\
\hline & Deltapaz & 3.4 & $319.33 \pm 61.76$ & $462.00 \pm 17.95$ \\
\hline & Control & 0.0 & $>2880.00 \pm 0.00$ & $>2880.00 \pm 0.00$ \\
\hline & $\operatorname{LSD}(\mathrm{P}<0.05)$ & & 90.90 & 33.88 \\
\hline \multirow[t]{6}{*}{ HD } & Cydim super & 3.0 & $29.67 \pm 13.68$ & $73.67 \pm 41.67$ \\
\hline & Pyrinex & 1.1 & $29.67 \pm 7.14$ & $43.66 \pm 6.64$ \\
\hline & Diazol & 3.2 & $25.33 \pm 4.41$ & $30.67 \pm 6.33$ \\
\hline & Deltapaz & 4.0 & $153.00 \pm 14.53$ & $431.33 \pm 14.70$ \\
\hline & Control & 0.0 & $>2880.00 \pm 0.00$ & $>2880.00 \pm 0.00$ \\
\hline & $\operatorname{LSD}(\mathrm{P}<0.05)$ & & 30.50 & 63.62 \\
\hline
\end{tabular}

$\mathrm{LD}=$ Lowest Doses, $\mathrm{MD}=$ Median Doses, $\mathrm{HD}=$ Highest Doses

At the highest dose trials with freshly treated panels, the mean lethal time for 50 and $90 \%\left(\mathrm{LT}_{50}\right.$ and $\left.\mathrm{LT}_{90}\right)$ of the test insects for Cydim Super, Pyrinex and Diazol were not significant $(P>0.05)$. Deltapaz acted significantly faster $(\mathrm{P}<0.05)$ than control, but gave a significantly higher $(\mathrm{P}<0.05)$ mean mortality time than Pyrinex, Cydim Super and Diazol.

\subsubsection{Three-day-old Treated Panels}

On the three-days-old treated panels, the results showed that, at lowest doses, Diazol and Pyrinex had the least mean mortality times $\left(\mathrm{LT}_{50}=27.67 \pm 3.38,38.00 \pm 4.58 ; \mathrm{LT}_{90}=40.00 \pm 5.00,53.00 \pm 9.00 \mathrm{~min}\right.$, respectively) (Table 2). The two treatments were, however, not significantly different $(\mathrm{P}>0.05)$ from each other. Mean lethal time $\left(\mathrm{LT}_{50}\right.$ and $\left.\mathrm{LT}_{90}\right)$ were significantly higher for Cydim Super compared to both Pyrinex and Diazol, but significantly lower than Deltapaz and the control $(\mathrm{P}<0.05)$. The control had a significantly higher mortality times $\left(\mathrm{LT}_{50}\right.$ and $\left.\mathrm{LT}_{90}>2880.0 \mathrm{~min}\right)$ than all the treatments. 
At the median dose levels on the 3-day-old treated panels, mean $\mathrm{LT}_{50}$ and $\mathrm{LT}_{90}$ values for Pyrinex, Cydim Super and Diazol were not significantly different $(\mathrm{P}>0.05)$ from each other. All these treatments however, acted significantly faster than Deltapaz $\left(\mathrm{LT}_{50}=669.67 \pm 136.0 \mathrm{~min}\right)$ and the control, which gave a significantly higher $(\mathrm{P}<0.05)$ mean $\mathrm{LT}_{50}$ values $\left(\mathrm{LT}_{50}>2880.0 \mathrm{~min}\right)$ compared to all the four treatments.

The highest doses of all the four insecticides acted significantly faster $(\mathrm{P}<0.05)$ than the control. Mean mortality times for pyrinex, Cydim Super and Diazol were not significantly different $(\mathrm{P}>0.05)$ from each other. The differences in mean mortality for Deltapaz and other three treatments (Cydim Super, Pyrinex and Diazol) were significant $(\mathrm{P}<0.05)$.

\subsubsection{Six-day-old Treated Panels}

The highest mean mortality time $\left(\mathrm{LT}_{50}\right.$ and $\left.\mathrm{LT}_{90}\right)$ of $1335.00 \pm 33.7$ and $1733.00 \pm 2.38$ min was obtained from panels treated with Deltapaz (Table 3) on the 6- day-old panels treated with the lowest doses. This was significantly higher $(\mathrm{P}<0.05)$ than the mean lethal times obtained from Cydim Super, Diazol and Pyrinex. Though, Cydim Super acted slower than the Pyrinex and Diazol, mean lethal times were not significantly different $(\mathrm{P}>0.05)$ from each other. The control gave significantly higher $(\mathrm{P}<0.05)$ mean mortality time than all the treatments.

Table 2. Mean Lethal Time (LT) of four insecticides on 3 days old treated panels

\begin{tabular}{|c|c|c|c|c|}
\hline \multirow[b]{2}{*}{ Dose level } & \multirow[b]{2}{*}{ Treatment } & \multirow[b]{2}{*}{ Doses $(\mathrm{ml} / \mathrm{L})$} & Mean \pm S. E. Lethal & \multirow{2}{*}{$\frac{\text { time }(\mathrm{min})}{\mathrm{LT}_{90}}$} \\
\hline & & & $\mathrm{LT}_{50}$ & \\
\hline LD & $\begin{array}{l}\text { Cydim Super } \\
\text { Pyrinex } \\
\text { Diazol } \\
\text { Deltapaz } \\
\text { Control } \\
\text { LSD }(\mathrm{P}<0.05)\end{array}$ & $\begin{array}{l}1.0 \\
0.9 \\
1.8 \\
2.6 \\
0.0\end{array}$ & $\begin{array}{l}127.00 \pm 54.20 \\
38.00 \pm 4.58 \\
27.67 \pm 3.38 \\
1291.00 \pm 29.20 \\
>2880.00 \pm 0.00 \\
39.10\end{array}$ & $\begin{array}{l}194.00 \pm 72.00 \\
53.00 \pm 9.00 \\
53.00 \pm 9.00 \\
1691.00 \pm 51.00 \\
>2880.00 \pm 0.00 \\
90.80\end{array}$ \\
\hline MD & $\begin{array}{l}\text { Cydim Super } \\
\text { Pyrinex } \\
\text { Diazol } \\
\text { Deltapaz } \\
\text { Control } \\
\text { LSD }(\mathrm{P}<0.05)\end{array}$ & $\begin{array}{l}2.3 \\
1.0 \\
2.5 \\
3.4 \\
0.0\end{array}$ & $\begin{array}{l}66.00 \pm 17.40 \\
33.33 \pm 4.41 \\
24.00 \pm 3.06 \\
669.67 \pm 136.01 \\
>2880.00 \pm 0.00 \\
193.40\end{array}$ & $\begin{array}{l}105.33 \pm 27.51 \\
41.67 \pm 4.63 \\
38.33 \pm 5.36 \\
844.67 \pm 96.49 \\
>2880.00 \pm 0.00 \\
141.70\end{array}$ \\
\hline HD & $\begin{array}{l}\text { Cydim Super } \\
\text { Pyrinex } \\
\text { Diazol } \\
\text { Deltapaz } \\
\text { Control } \\
\text { LSD }(\mathrm{P}<0.05)\end{array}$ & $\begin{array}{l}3.0 \\
1.1 \\
3.2 \\
4.0 \\
0.0\end{array}$ & $\begin{array}{l}44.67 \pm 14.66 \\
19.33 \pm 5.28 \\
13.67 \pm 2.27 \\
411.67 \pm 246.68 \\
>2880.00 \pm 0.00 \\
344.10\end{array}$ & $\begin{array}{l}60.33 \pm 1.46 \\
31.00 \pm 3.00 \\
28.67 \pm 4.70 \\
771.67 \pm 93.18 \\
>2880.00 \pm 0.00 \\
134.10\end{array}$ \\
\hline
\end{tabular}

$\mathrm{LD}=$ Lowest Doses, MD = Median Doses, HD = Highest Doses

There was no significant difference $(\mathrm{P}>0.05)$ between the mortality times on panels treated with median doses of Cydim Super, Pyrinex, and Diazol after 6 days. However, apart from the control that gave significantly higher $(\mathrm{P}<0.05)$ mortality times than all the treatments, Deltapaz was significantly less toxic $(\mathrm{P}<0.05)$ against the adult flies compared with Cydim Super, Pyrinex and Di. 
Table 3. Mean Lethal time (LT) of four insecticides on 6-day-old treated panels

\begin{tabular}{lllll}
\hline \multirow{2}{*}{ Dose level } & & & \multicolumn{2}{l}{ Mean \pm S. E. Lethal time $(\mathrm{min})$} \\
\cline { 5 - 5 } & Treatment & Dose $(\mathrm{ml} / \mathrm{L})$ & $\mathrm{LT}_{50}$ & $\mathrm{LT}_{90}$ \\
\hline & Cydim super & 1.6 & $144.33 \pm 55.47$ & $199.66 \pm 129.66$ \\
& Pyrinex & 0.9 & $34.44 \pm 2.33$ & $48.33 \pm 4.10$ \\
& Diazol & 1.8 & $24.67 \pm 3.38$ & $30.66 \pm 3.38$ \\
& Deltapaz & 2.6 & $1335.00 \pm 33.76$ & $1733.67 \pm 209.83$ \\
& Control & 0.0 & $>2880.00 \pm 0.00$ & $>2880.00 \pm 0.00$ \\
& LSD $(\mathrm{P}<0.05)$ & & 91.70 & 347.77 \\
\hline MD & Cydim Super & 2.3 & $74.33 \pm 17.32$ & $94.33 \pm 21.30$ \\
& Pyrinex & 1.0 & $37.33 \pm 1.20$ & $50.00 \pm 6.11$ \\
& Diazol & 2.5 & $19.00 \pm 1.16$ & $26.33 \pm 3.38$ \\
& Deltapaz & 3.4 & $1277.00 \pm 38.76$ & $1459.00 \pm 51.08$ \\
& Control & 0.0 & $>2880.00 \pm 0.00$ & $>2880.00 \pm 0.00$ \\
& LSD $(\mathrm{P}<0.05)$ & & 59.84 & 78.60 \\
\hline \multirow{3}{*}{ HD } & Cydim super & 3.0 & $42.67 \pm 9.74$ & $62.00 \pm 17.67$ \\
& Pyrinex & 1.1 & $26.33 \pm 1.45$ & $35.33 \pm 1.33$ \\
& Diazol & 3.2 & $14.67 \pm 2.33$ & $20.66 \pm 1.86$ \\
& Deltapaz & 4.0 & $790.00 \pm 147.31$ & $1110.33 \pm 205.00$ \\
& Control & 0.0 & $>2880.00 \pm 0.00$ & $>2880.00 \pm 0.00$ \\
& LSD $(\mathrm{P}<0.05)$ & & 208.10 & 290.00 \\
\hline
\end{tabular}

$\mathrm{LD}=$ Lowest Doses, $\mathrm{MD}=$ Median Doses, $\mathrm{HD}=$ Highest doses

Results obtained with the highest doses were very similar to those in the median doses. Cydim Super gave higher mean mortality times $\left(\mathrm{LT}_{50}\right.$ and $\left.\mathrm{LT}_{90}\right)$ than those obtained on panels treated with Pyrinex and Diazol, but the differences among the means were not significant $(\mathrm{P}>0.05)$. Mean mortality times for Deltapaz $\left(\mathrm{LT}_{50}\right.$ and $\mathrm{LT}_{90}$ $=153.00 \pm 14.53$ and $431 \pm 14.70 \mathrm{~min}$, respectively $)$ were significantly higher $(\mathrm{P}<0.05)$ than all the three treatments, but significantly lower $(\mathrm{P}<0.05)$ than control $\left(\mathrm{LT}_{50}\right.$ and $\left.\mathrm{LT}_{90}>2880.0 \mathrm{~min}\right)$ (Table 3$)$.

The pattern of toxicity of 6-day old treated panels was similar to that of the freshly treated panels. Deltapaz, however, showed a progressive decrease in toxicity with increase in the age of residues.

\section{Discussion}

\subsection{Susceptibility Bioassays}

The adult susceptibility bioassay of the field strain of the adult $B$. invadens flies demonstrated differential susceptibility to Cydim super, Pyrinex, Diazol and Deltapaz. Bactrocera invadens was comparatively more susceptible to Pyrinex 48 EC (chlorpyrifos) and Diazol 50 EW (Diazinon) than to the other insecticides (Cydim Super and Deltapaz). Raga and Sato (2006) found the lowest $\mathrm{LT}_{50}$ value for malathion against Anestrapha fraterculus (Weidemann) adults under cover spray trials. Many factors affect the intrinsic toxicities of insecticides to insects including, volatilization, storage in inner tissues, transport from contact site to target site, detoxification, excretion and competition with normal enzymes at the respective sites (Brooks, 1976).

The least degree of susceptibility to Deltapaz (Deltamethrin) observed in this study is similar to that reported by Barry and Polavarapu (2005) on Rhagoletis mendax Curran (Diptera: Tephritidae) where knockdown or mortality of the pyretroids, Deltamethrin was not significant enough to warrant its further evaluation on $R$. mendax. Barry et al. (2004) also confirmed this when investigating insecticidal coatings for spheres used to attract and kill $R$. mendax. 
The current study showed that Diazol $50 \mathrm{EW}$ (Diazinon) when applied at the rate of $1.8 \mathrm{ml} / \mathrm{L}$ acted faster than the other insecticides. This implies that at this dose the flies were more susceptible to Diazol than the other insecticidal products. However, differences between lethal times for Cydim Super, Pyrinex and Diazol were not significant $(\mathrm{P}>0.05)$ at this level of application. This suggest that, it will be more economical for the resource poor farmers to use Pyrinex which had the application rate of $0.9 \mathrm{ml} / \mathrm{L}$ compared to $1.6 \mathrm{ml} / \mathrm{L}, 1.8 \mathrm{ml} / \mathrm{L}$ and 2.6 $\mathrm{ml} / \mathrm{L}$ for Cydim Super, Diazol and Deltapaz, respectively.

At the recommended dose levels, all three insecticides namely, Cydim Super, Pyrinex and Diazol were not significantly different from each other at the $\mathrm{LT}_{50}$ levels. At the $\mathrm{LT}_{90}$ values, Cydim super $(103.00 \pm 14.18 \mathrm{~min})$ was significantly longer than Diazol and Pyrinex. Thus, adults of $B$. invadens were less susceptible to Cydim super compared to Pyrinex and Diazol.

The toxicities of the insecticides was dose-dependent. The optimum dose for the control under field conditions needs to be determined through further studies, in which the damage levels after treatments are related to the doses of tested insecticides.

Diazol always acted faster than the other insecticidal products. There was a general gradual reduction in the toxicities of the insecticides to adult flies with increase in age of residues. Deltapaz however, displayed least toxicity on the flies. This implies that the residual toxicity of Deltapaz was low and so when used for $B$. invadens control in the field, it may need more frequent application since its mortality times increased more than 3 -fold over the six-day period of evaluation. However, if the pest population is equally low, it could be of good insecticide for fly control especially close to harvest time, where the likelihood of residue build up/ accumulation in fruits may be minimal.

However, the application rate of Pyrinex was the lowest in $\mathrm{ml} / \mathrm{L}$ compared to those of the other insecticides. Pyrinex was used at the $0.09 \%(0.9 \mathrm{ml} / \mathrm{L}), 0.1 \%(1.0 \mathrm{ml} / \mathrm{L})$ and $0.11 \%(1.1 \mathrm{ml} / \mathrm{L})$ compared to the other insecticides.

\section{Acknowledgement}

We gratefully acknowledge the German Academic Exchange Service (DAAD) for funding this research.

\section{References}

Barry, J. D., \& Polavarapu, S. R. (2005). Feeding and survivorship of blueberry maggot flies (Diptera: Tephritidae) on protein baits incorporated with insecticides. Florida Entomologist, 88(3), 268-277.

Barry, J. D., Polavarapu, S., \& Teixeira, L. A. F. (2004). Evaluation of traps and toxicants in an attract-and-kill system for Rhagoletis mendax (Diptera: Tephritidae). Journal of Economic Entomology, 97, 2006-2014.

Billah, M. K., Wilson, D. D., Cobblah, M. A., Lux, S. A., \& Tumfo, J. A. (2006). Detection and preliminary survey of the new invasive Fruit fly species Bactrocera invadens (Diptere: Tephritidae) in Ghana. Journal of the Ghana Science Association, 8(2), 139-149.

Billah, M. K., \& Mansell, M. W. (2006). Fruit fly taxonomy, pp. H 1- 19. In: Ekesi, S., \& Billah, M. K. (eds). A field guide to the management of economically important Tephritid fruit fly in Africa, ICIPE Science Press, Nairobi, Kenya, pp. 206.

Brooks, G. T. (1976). Insecticide biochemistry and physiology. In Wilkinson, C. F. (ed.), Insecticide biochemistry and Physiology. Plenum, New York, pp. 3-58.

Cheng, C. L., Cho, I. K., \& LI, Q. X. (2009). Insecticidal activity of Basil Oil, trans-Anethole, Estragole, and Linalool to adult fruit flies of Ceratitis capitata, Bactrocera dorsalis, and Bactrocera cucurbitae. Journal of Economic Entomology, 102(1), 203-209.

Copeland, R. S. (2006). Host fruit processing- purpose, tools and methodology, F1 - 11. In: Ekesi S. and Billah, M. K. (eds.). A Field Guide to the management of economically important Tephritid fruit flies in Africa, ICIPE Science Press Nairobi, Kenya, pp. 206.

CTA. (2007). How to Control the Mango Fruit Fly. CTA practical guide series, 14, 6.

De Meyer, M. (1996). Revision of the sub-genus Ceratitis (Pardalapis) Bezzi, 1918 (Diptera: Tephritidae, Ceratini). Systematic Entomology, 21, 15-26.

De Meyer, M. (1998). Revision of the subgenusn Ceratitis (Ceratalaspis) Hancook (Diptere: Tephritidae). Bulletin of Entomological Research, 88, 439-467. 
De Meyer, M. (2000). Systematic revision of the subgenus Ceratitis Macleay (Diptera: Tephritidae) 2001. Journal of the Linneaus Society of London, 128, 439-467.

De Meyer, M., Mohammed, S., \& White, I. M. (2007). An invasive fruit flies in Africa. A diagnostic tool and information reference for the Asian species of fruit flies (Diptera: Tephritidae) that have become accidentally established as pests in Africa, including the Indian Oceans Islands. http://www.africanmuseum.be/fruitfly/AfroAsia.htm

Drew, R. A. I., Tsuruta, K., \& White, I. M. (2005). A new species of pest fruit fly (Diptera: Tephritidae: Dacinae) from Sri Lanka and Africa. African Entomology, 13, 149-154.

Ekesi S., \& Billah, M. K. (2006). A Field Guide to the management of economically important Tephritid fruit flies in Africa. ICIPE Science Press Nairobi, Kenya, pp. 206.

Ekesi, S., Nderitu, P. W., \& Rwomushana, I. (2006). Field infestation and demographic parameters of the fruit fly Bactrocera invadens (Diptera: Tephritidae) in Africa. Bulletin of Entomological Research, 96, 379-386.

EPA. (2008). List of recommended insecticides for horticultural crops in Ghana. http://www.epaghana.gov.

ICIPE. (2007). Development and implementation of a sustainable IPM program for major mango pests and opportunity for improving market information and processing in sub-Saharan Africa. http://www.gtz.de./de/dokumente/en-ICIPEproject1-2007.html

ISSER. (2008). The state of the Ghanaian economy in 2007. Institute of Statistics, Social and Economic Research (ISSER), University of Ghana, Legon, pp. 236.

Lux, S. A., Copeland, R. S., White, I. M., Manrakhan, A., \& Billah, M. K. (2003b). A new invasive fruit fly species from the Bactrocera dorsalis (Hendel) group detected in East Africa. Insect Science Application, $23,355-361$.

Moore, D. J., \& Miller, D. M. (2006). Laboratory evaluation of insecticide product efficacy for the control of Cimex lectularius. Journal of Economic Entomology, 99(6), 2080-2086.

Moreno, D., Martinez, A. J., Riviello, M. S. (1994). Cyromazine effects on the reproduction of Anastrepha ludens (Diptera: Tephritidae) in the laboratory and the field. Journal of Economic Entomology, 87(1), 202-211.

Raga, A., \& Sato, M. E. (2006). Time-mortality for fruit flies (Diptera: Tephritidae) exposed to insecticides in laboratory. Neotropical Entomology, 73(1), 73-77.

Rwomushana, I., Ekesi, S., Gordon, I., \& Ogal, C. K. P. (2008). Host plants and host plant preference studies for Bactrocera invadens (Diptera: Tephritidae) in Kenya, a new invasive fruit fly species in Africa. Annals of the Entomological Society of America, 101(2), 331-340.

Urbaneja, A., Chueca, P. Monto'n, H., Pascual-ruiz, S., Dembilio, O., Vanaclocha, P., Abad, Moyano, ... CastañEra. (2009). Chemical alternatives to Malathion for controlling Ceratitis capitata (Diptera: Tephritidae), and their side effects on natural enemies in Spanish citrus orchards. Journal of Economic Entomology, 102(1), 203-209.

White, I. M., \& Elson-Harris, M. M. (1992). Fruit flies of economic significance: their identification and bionomics. CAB International, Wallingford, United Kingdom. pp. 601. 